\title{
Bozburun Yarımadası (Marmaris-Muğla) Florasına Katkılar
}

\author{
Kenan AKBAŞ ${ }^{* 1}$, Ömer VAROL ${ }^{2}$ \\ ${ }^{1}$ Muğla Sitkı Koçman Üniversitesi, Köyceğiz Meslek Yüksekokulu, Bitkisel ve Hayvansal Üretim Bölümü, 48800, \\ Muğla \\ 2Muğla Sıtkı Koçman Üniversitesi, Fen Fakültesi, Biyoloji Bölümü, 48000, Muğla
}

(Alınış / Received: 04.04.2019, Kabul / Accepted: 11.10.2019, Online Yayınlanma / Published Online: 30.12.2019)

\section{Anahtar Kelimeler}

Bozburun,

Floraya katkılar,

Marmaris,

Muğla
Özet: Bu çalıșma, Bozburun Yarımadası'nın (Marmaris-Muğla) floristik yapısına katkı sağlamak amacıyla gerçekleştirilmiştir. Araştırma alanı Davis'in kullandığı kareleme sistemine göre C1 ve C2 karesinde bulunmaktadır. Çalışmamızda, Nisan 2013 - Haziran 2015 tarih aralığında çalışma alanından toplanan bitki örnekleri değerlendirilmiş olup 470 bitki taksonu tayin edilmiştir. Bu taksonlardan 27 tanesi mevcut floraya ilave olarak tespit edilmiştir. Bu ilave bitki taksonlarından, 7 (\% 26) adeti Akdeniz elementi, 5 (\%19) adeti Doğu Akdeniz elementi, 3 (\% 11) adeti Avrupa-Sibirya elementidir. Ayrıca, taksonların 12 (\% 44) tanesi ya geniş yayılışlı ya da fitocoğrafik bölgesi bilinmemektedir. Endemik bitki taksonlarl 4 adettir.

\section{Contributions to The Flora of Bozburun Peninsula (Marmaris-Muğla)}

\section{Keywords}

Bozburun,

Contributions to the flora,

Marmaris,

Muğla

\begin{abstract}
This study was carried out to contribute to the floristic structure of Bozburun Peninsula (Marmaris-Muğla). The research area is located in C1 and C2 square according to the grid system used by Davis. In this study, between April 2013-June 2015, by evaluating the collected plant specimens, 470 plant taxa were identified. 27 of these taxa have been identified in addition to the existing flora. Of these additional plant taxa are 7 (\% 26) Mediterranean elements, 3 (\% 11) are European-Siberian elements and $5(\% 19)$ are East Mediterranean elements. Moreover, 12 (\% 44) of the taxa is either widespread or the phytogeographical region is not known. The endemic plants are 4.
\end{abstract}

\section{Giriş}

Bozburun Yarımadası güneybatı Anadolu'da Marmaris ilçesinin (Muğla) sınırları içerisinde bulunmakta ve Datça-Bozburun önemli doğa alanı içerisinde yer almaktadır. Ayrıca İçmeler, Turunç ve Kumlubük'ü kapsayan bölge Marmaris Milli parkının güney-batı kısmını oluşturmaktadır (Şekil 1).

Çalışma alanı, oldukça az bozulmuş Akdeniz bitki örtüsünü içermektedir. Bu bitki örtüsü kireç taşı ve serpantin kayaçlarda gelişme gösteren boylu frigana, maki, kızılçam ormanları, kumul bitkileri ve günlük ağacı topluluklarıdır. Çalışma alanı oldukça dağlık bir özellik göstermektedir ve bir kısmı 500 m'den yüksek 20 kadar dağ ve tepe içermektedir. Aynı zamanda alanda yaklaşı 25 kadar koy bulunmaktadır [1].
Carlström tarafından Yunanistan'a bağlı Rodos, Tilos ve Simi adaları ile birlikte Datça ve Bozburun Yarımadalarını (Marmaris-Muğla) kapsayan bir bölgede gerçekleștirilmiş floristik bir araştırma bulunmaktadır [2]. Yarımadanın floristik yapısının belirlenmesiyle tarafımızdan alanda bir vejetasyon araştırması doktora tez çalışması olarak gerçekleştirilmiştir.

$\mathrm{Bu}$ çalışma neticesinde belirlediğimiz bitki taksonları ile Carlström [2]' un yapmış olduğu floristik araştırmada belirlenen bitkiler karşılaştırılmış ve daha önce alandan tespit edilmeyen taksonlar not edilmiştir.

Araştırma alanı Davis'in kullandığı kareleme sisteme göre C2 karesi içerisinde, yarımadanın batı kısmında çok ufak bir bölümü ise C1 karesi sınırları içerisinde konumlanmaktadır [3]. 


\subsection{Araştırma alanının jeolojik yapısı ve büyük toprak grupları}

Çalışma alanının büyük toprak gruplarını içeren harita, "Muğla İli Arazi Varlığı" isimli kaynaktan yararlanılarak çizilmiştir [4]. Araştırma alanının büyük toprak grupları; kireçsiz kahverengi orman toprakları, kırmızı kahverengi Akdeniz toprakları, çıplak kaya ve molozlar, kırmızı Akdeniz toprakları ve kolüvyal topraklardır (Şekil 2).

Bölgenin jeoloji haritası Maden Tetkik Arama (MTA)'nın hazırlamış olduğu paftalardan yararlanarak çizilmiştir. Jeoloji haritasında belirlenen formasyonlara ait bilgiler Şenel ve Bilgin (1997)'nin yapmış olduğu çalışmadan faydalanılarak yazılmıştır [5].

Çalışma alanında yer alan jeolojik oluşumlar Göçgediği formasyonu, Güverdağı formasyonu, Karanasiflar formasyonu, Orluca formasyonu, Orhaniye formasyonu ve Marmaris Peridotiti birimlerinden meydana gelmektedir (Şekil 3).

\subsection{Araştırma alanının iklimsel özellikleri}

Çalışma sahasının iklim bilgileri, Muğla Meteoroloji Müdürlügü'nün Marmaris'e ait raporlarından temin edilmiştir. Elde edilen verilerle Marmaris'in iklim diyagramı çizilmiştir (Şekil 4). Marmaris istasyonunun yıllık sıcaklık ortalaması $18.7{ }^{\circ} C^{\prime}$ dır. Yıllık toplam yağıș miktarı 1258.2 mm'dir. YağıȘ rejimi KISY olup, Merkezi Akdeniz yağış rejimi tipine sahiptir [6]. Alınan verilere göre Köyceğiz Yağışlı Ilık Akdeniz İklimi, Muğla Yağışlı Serin Akdeniz İklimine sahiptir (Tablo 1).

Şekil 4'te; a. Meteoroloji istasyonunun adl, b. Meteoroloji istasyonunun rakımı (m), c. Sicaklık rasat süresi, d. Yağış rasat süresi, e. Yıllık ortalama sıcaklık, f. Yıllık toplam yağış miktarı (mm), g. Sıcaklık eğrisi, h. Yağış eğrisi, i. Kurak periyot, k. Yağıșlı periyodunu ifade eder.

\section{Materyal ve Metot}

Bozburun yarımadası'nda Nisan 2013-Haziran 2015 tarihleri arasında yapılan arazi çalışmaları neticesinde 470 bitki taksonu tespit edilmiştir. Toplanan bitki numunelerinin tayininde "Türkiye ve Doğu Ege Adalarının Florası" [7; 8] isimli kaynaklardan faydalanılmıştır. Belirlenen bitki taksonlarının adları "Türkiye Damarlı Bitki Listesine" göre yeniden revize edilmiştir [9]. Araştırma konusunu oluşturan bitki türleri herbaryum materyali haline getirilerek Muğla Sıtkı Koçman Üniversitesi, Herbaryum Laboratuvarında muhafaza edilmektedir.

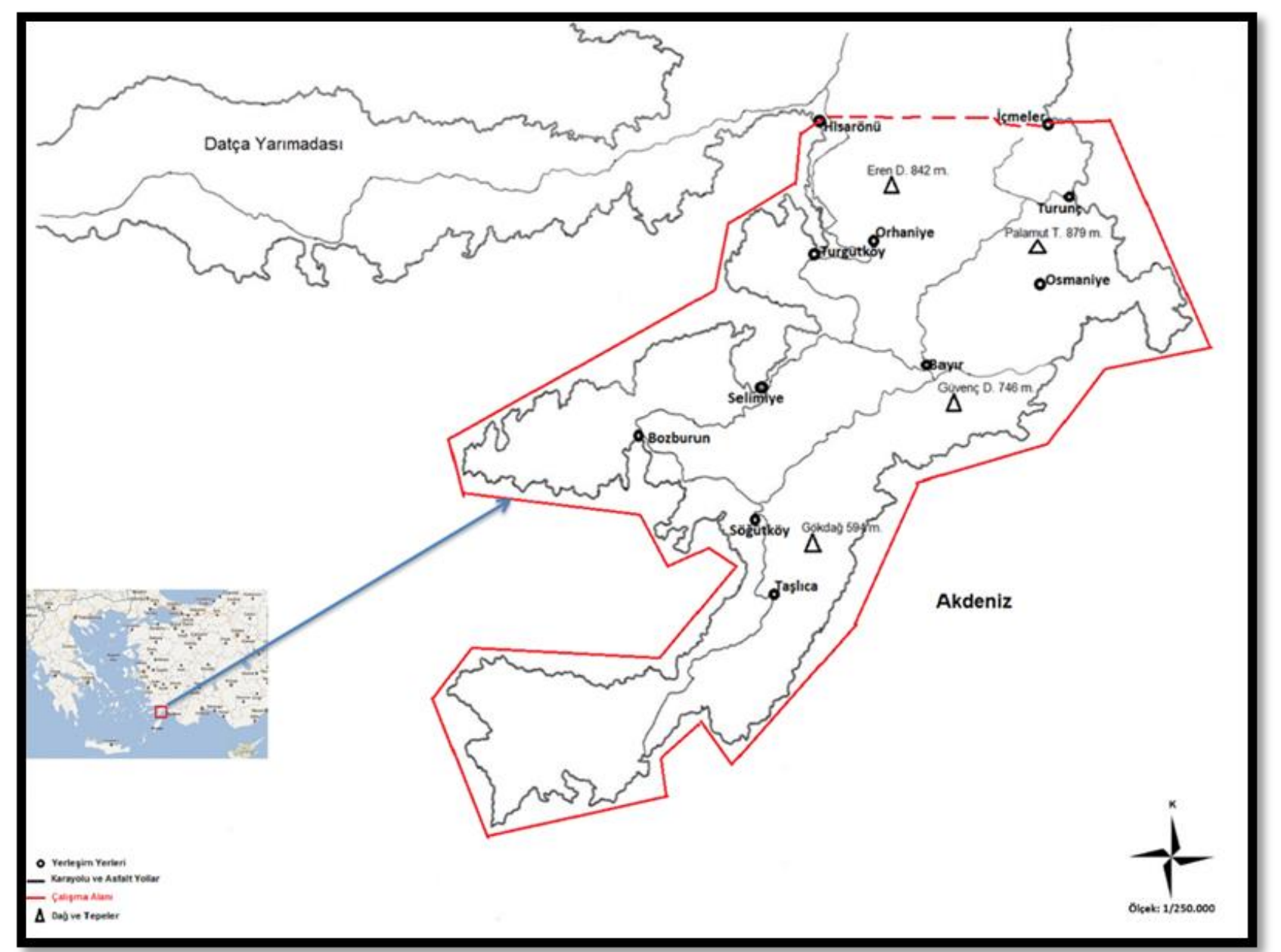

Şekil 1. Araştırma Alanı Haritası 


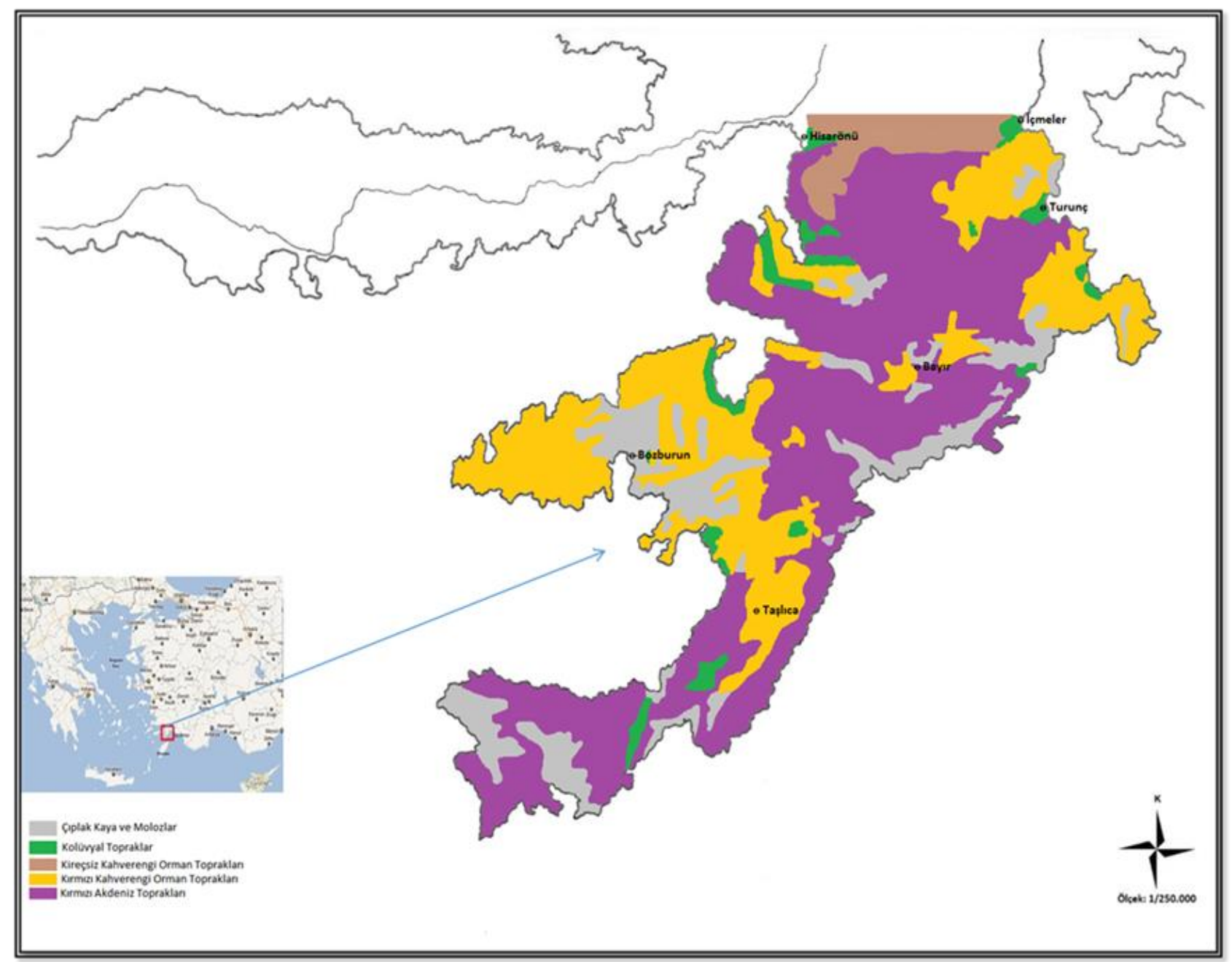

Şekil 2. Araştırma alanında toprak gruplarının dağılıșı

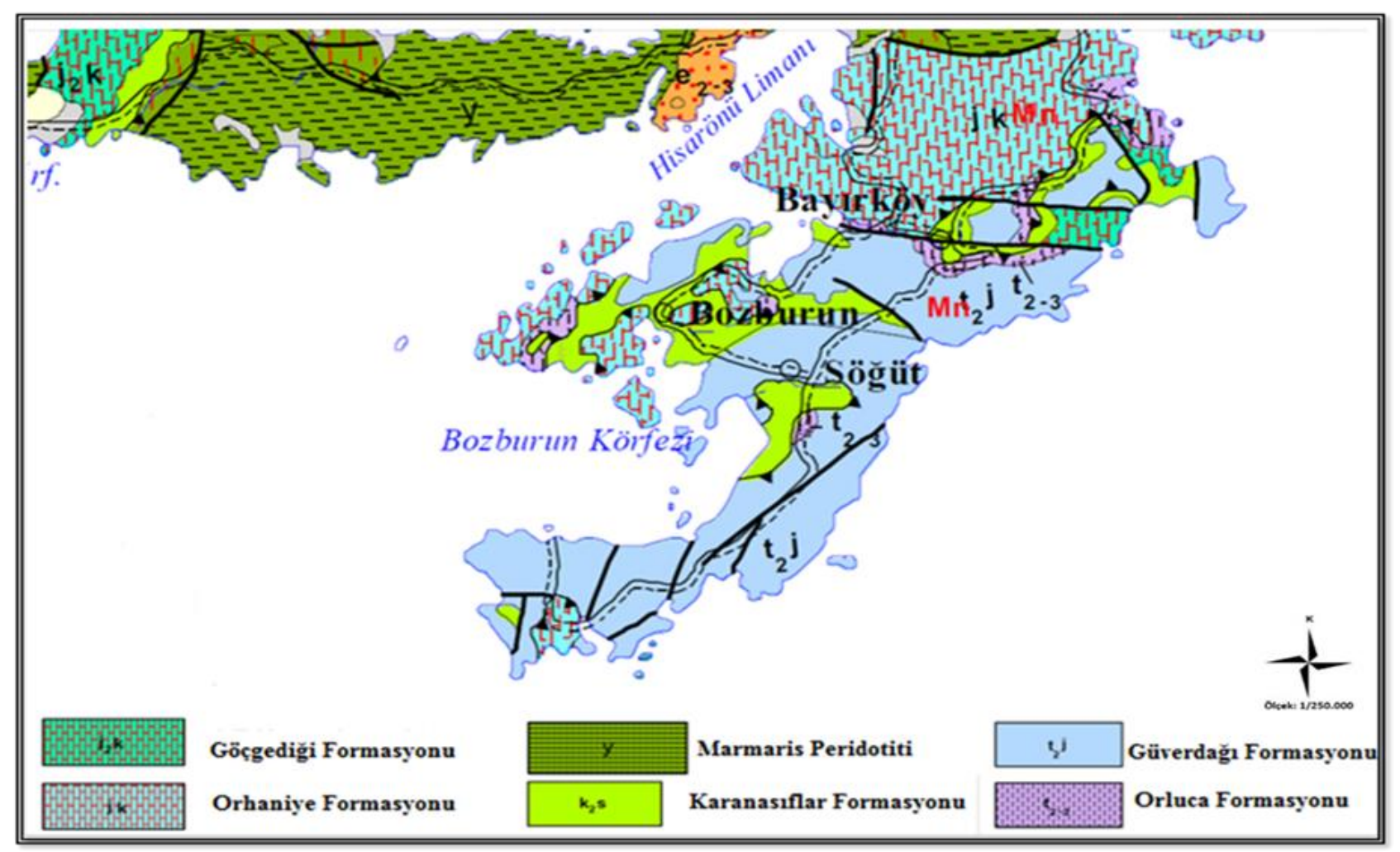

Şekil 3. Çalışma alanının jeoloji haritası 


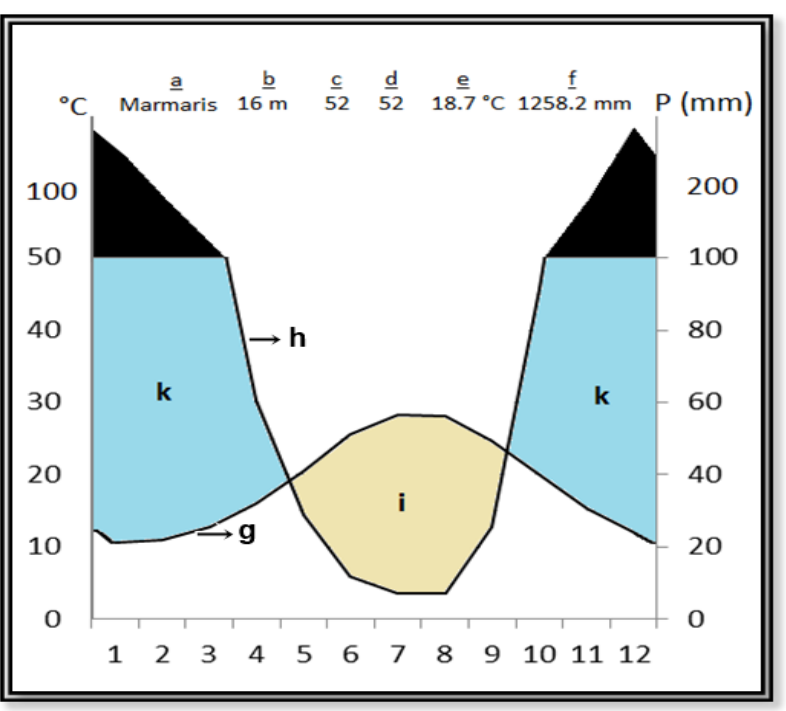

Şekil 4. Marmaris istasyonu ombrotermik diyagramı

Tablo 1. İstasyonların biyoiklim analizi tablosu

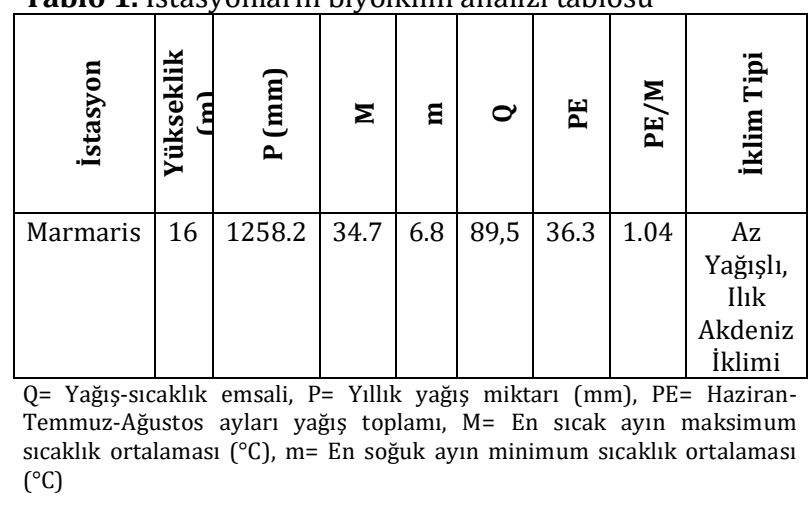

Kisaltmalar;

Akd. Ele.: Akdeniz Elementi

D. Akd. Ele.: Doğu Akdeniz Elementi

Avr.-Sib. Ele.: Avrupa-Sibirya Elementi

End.: Endemik

K.A.: Kenan AKBAŞ

m: Metre

$\mathrm{km}$ : Kilometre

\section{Bulgular}

\subsection{Floristik liste}

\section{PAPAVERACEAE}

Fumaria officinalis L.

Muğla; Marmaris, Selimiye'ye gelmeden 3-4 km. önceki zeytinlik tepeler, 80 m, 18.04.2015, K.A. 775a

\section{BRASSICACEAE}

Iberis carica Bornm. End.

Muğla; Marmaris, İçmeler-Hisarönü sapağından, Hisarönüne giderken yol üzeri garig tepelikleri, 220 m, 13.04.2015, K.A. 774, D. Akd Ele.

\section{CARYOPHYLLACEAE}

Arenaria rhodia Boiss. var. macropetala McNeill End.
Muğla; Marmaris, Söğüt-Taşlıca arası, Taşlıca'ya gelmeden önce yol üzerindeki makilik tepeler, 240 m, 02.05.2015, K.A. 827-a, D. Akd Ele.

Stellaria neglecta (Weihe) Gremli

Muğla; Marmaris, Selimiye'ye gelmeden 3-4 km. önceki zeytinlik tepeler, 37 m, 16.03.2014, K.A. 649a

\section{POLYGONACEAE}

Rumex tuberosus L. subsp. tuberosus

Muğla; Marmaris, Bayırdan Söğüt arası, tarihi su sarnıcı çevresi, Bozen gediği mevkii makilik alanlar, 366 m, 26.04.2014, K.A. 731-a

\section{LINACEAE}

Linum corymbulosum Reichb.

Muğla; Marmaris, Selimiye, Kamelya adası karşısındaki makilik tepelikler, 266 m, 22.04.2015, K.A. 787-a, Akd. Ele.

\section{FABACEAE}

Pisum sativum L. subsp. elatius (Bieb.) Aschers. etGraebn. var. pumilio Meikle

Muğla; Marmaris, Bayırdan Söğüt arası, tarihi su sarnıcı çevresi, Bozen gediği mevkii makilik alanlar, $360 \mathrm{~m}, 27.04 .2014$, K.A. 740

Pisum sativum L.subsp. elatius (Bieb.) Aschers. et Graebn. var. elatius

Muğla; Marmaris, Bayırdan Söğüt arası, makilik alanlar, 396 m, 13.04.2014, K.A. 708-a, Akd. Ele.

Vicia sativa L.subsp. nigra (L.) Ehrh. var. nigra Muğla; Marmaris, Selimiye'ye gelmeden 3-4 km. önceki zeytinlik tepeler, 80 m, 18.04.2015, K.A. 778a

Cicer montbretii Jaub\&Spach

Muğla; Marmaris, Osmaniye köyü, Sarnıç Mah. Çevresi, Pinus brutia ormanı, 536 m, 23.05.2015, K.A. 862, D. Akd. Ele.

\section{ROSACEAE}

Rosa canina $\mathrm{L}$.

Muğla; Marmaris, İçmeler-Turunç yolu, Pinus brutia ormanı, 409 m, 18.05.2014, K.A. 744-a

Agrimonia eupatoria L. subsp. eupatoria Muğla; Marmaris, İçmeler-Turunç yolu, TurunçOsmaniye yol ayrımı, Pinus brutia ormanı, 388 m, 19.05.2014, K.A. 749-a

Rubus canescens DC. var. canescens

Muğla; Marmaris, İçmeler-Hisarönü yol ayrımından Hisarönüne giderken yolun sol tarafi, Kuruandız mevkii, Pinus brutia ormanı, 435 m, 20.05.2015, K.A. 860-a, Avr.-Sib. Ele.

\section{CAPRIFOLIACEAE}

Lonicera nummulariifolia Jaub. \&Spach subsp. glandulifera (Hub.-Mor.)Chamb. End. 
Muğla; Marmaris, Taşlıca'dan Serçe limanına inerken yol üzeri makilik alanlar, $180 \mathrm{~m}$, 02.05.2015, K.A. 843, D. Akd. Ele.

\section{VALERIANACEAE}

Valerianella discoidea (L.) Loisel.

Muğla; Marmaris, Bayır-Söğüt arası, İsmail ağa mevkii, Makilik alanlar, 339 m, 22.03.2014, K.A. 660-a, Akd. Ele.

\section{ASTERACEAE}

Carduus pycnocephalus L. subsp. pycnocephalus Muğla; Marmaris, Bayır-Söğüt arası, İsmail ağa mevkii, Makilik alanlar, 339 m, 22.03.2014, K.A. 658

Carduus pycnocephalus L. subsp. arabicus (Jacq. exMurray) Nyman

Muğla; Marmaris, Turunç, Kumlubük yolu üzeri, Pinus brutia ormanı, 176 m, 12.05.2015, K.A. 850, Akd. Ele.

\section{GENTIANACEAE}

Centaurium erythraea Rafn.subsp. turcicum (Velen.) Melderis

Muğla; Marmaris, Turgut, gemi tersane çevresi, Pinus brutia ormanı, 75 m, 14.05.2015, K.A. 853

\section{SCROPHULARIACEAE}

Verbascum pinardii Boiss. End.

Muğla; Marmaris, Osmaniye-Camiyanı Mah. Eldire mevkii, Pinus brutia ormanı, 450 m, 28.05.2015, K.A. 873, D. Akd. Ele.

\section{OROBANCHACEAE}

Orobanche minor SM.

Muğla; Marmaris, Selimiye-Kamelya adası arasında kalan frigana tepeleri, 240 m, 22.04.2015, K.A. 800-a

\section{LAMIACEAE}

Lamium moschatum Miller. subsp. moschatum Muğla; Marmaris, Bayır-Sögüt arası, İsmail ağa mevkii, Makilik alanlar, 300 m, 23.03.2014, K.A. 673, Akd. Ele.

\section{FAGACEAE}

Quercus ilex L.

Muğla; Marmaris, İçmeler-Turunç yolu, Pinus brutia ormanı, 120 m, 18.05.2014, K.A. 742-a, Akd. Ele.

\section{RUBIACEAE}

Galium spurium L. subsp. spurium

Muğla; Marmaris, Bayırdan Söğüt arası, makilik alanlar, 380 m, 22.03.2014, K.A. 656-a, Avr.-Sib. Ele.

\section{ORCHIDACEAE}

Cephalanthera longifolia (L.) Fritsch

Muğla; Marmaris, İçmeler-Bayır yolu üzeri Palamut tepe, Pinus brutia ormanı, 830 m, 31.05.2015, K.A. 878-a, Avr.-Sib. Ele.
Cephalanthera rubra (L.) Rich

Muğla; Marmaris, Osmaniye-Bayır arası, yol zerindeki Pinus brutia ormanı, 580 m, 26.05.2015, K.A. 866-a

\section{POACEAE}

Bromus chrysopogon Viv.

Muğla; Marmaris, Bayırdan Sögüt arası, makilik alanlar, 360 m, 12.04.2014, K.A. 699-a, Akd. Ele.

Bromus hordeaceus L. subsp. hordeaceus

Muğla; Marmaris, Bayırdan Söğüt arası, tarihi su sarnıcı çevresi, Bozen gediği mevkii makilik alanlar, 370 m, 27.04.2014, K.A. 739-a

\section{Tartışma ve Sonuç}

Çalışma alanını da içerisine alan bir bölgede Carlström tarafından floristik bir araştırma gerçekleştirilmiştir [2]. Çalışma alanının vejetasyonunu belirlemek üzere toplanan bitkilerden 470 takson tespit edilmiştir. Belirlediğimiz bu bitki taksonlarından 18 familyaya ait 23 cins 13 tür, 9 alttür ve 5 varyetenin araştırma sahasında daha önceden tespit edilmediği belirlenmiştir.

Çalıșma alanımızdan toplanan endemik bitkilerin tehlike kategorileri IUCN kriterleri ve Türkiye bitkileri kırmızı kitabından bakılarak kategorize edilmiştir [10-11]. İlave edilen bitki türlerindeki endemik bitki taksonlarının sayısı 4'dür. Çalışma alanımızın neredeyse hemen hemen tamamında anakayanın kireç taşı olması ve yükseltinin düşük olması ilave edilen endemik bitki sayısının da düşük olmasının nedenini ortaya koymaktadır. İlave edilen endemik bitkilerden Arenaria rhodia var. macropetala maki açıklıklarındaki kaya çatlaklarında bulunmaktadır ve "EN-Tehlikede" tehlike kategorisinde yer almaktadır. Petallerinin büyüklüğü sebebiyle kültüre alınabilir özellik göstermektedir. Diğer endemik bitki taksonları "NTTehdit Altına Girebilir" tehlike kategorisinde bulunmaktadır. Ancak tahribatlar devam ettiği sürece "VU-Zarar Görebilir" kategorisinde yer alması muhtemeldir (Tablo 2).

Bitki örneklerinin \% 26'sı Akdeniz elementi, \% 19' u Doğu Akdeniz elementi, \% 11' i Avrupa-Sibirya elementi ve \% 44' ü Geniş yayılışlı veya yayılış alanı belirlenemeyen taksonlardan oluşmaktadır (Şekil 5). Göründüğ̈ gibi fitocoğrafik bölgesi bilinen bitki taksonlarının büyük çoğunluğunu Akdeniz ve Doğu Akdeniz elementleri oluşturmaktadır. $\mathrm{Bu}$ sonuç, araştırma alanının Akdeniz fitocoğrafik bölgesi sınırları içerisinde bulunmasının doğal bir sonucudur. 
Tablo 2. Araștırma alanındaki floraya ilave olarak bulunan endemik bitki taksonları ve tehlike kategorileri

\begin{tabular}{|c|c|}
\hline Endemik Bitkiler & Tehlike Kategorileri \\
\hline Iberis carica Bornm. & NT (Tehdit Altına Girebilir) \\
\hline Arenaria rhodia Boiss. var. macropetala McNeill & EN (Tehlikede) \\
\hline $\begin{array}{c}\text { Verbascum pinardii Boiss. } \\
\text { glandulifera (Hub.-Mor.)Chamb. }\end{array}$ & NT (Tehdit Altına Girebilir) \\
\hline
\end{tabular}

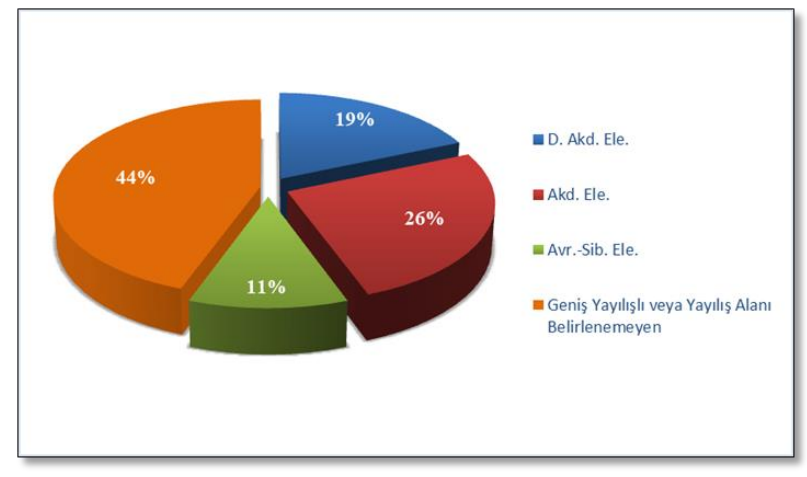

Şekil 5. Bitki taksonlarının fitocoğrafik bölgelere göre dağılımı

Araştırma sahasındaki bu bitki taksonları turizm, otlatma ve tarla açımı gibi nedenlerden ötürü tehdit altındadır. Bu amaçla, bu bölgede yaşayan yöre halkının bilgilendirilmesiyle bitkiler üzerindeki tehdit önemli ölçüde azaltılabilir. Ayrıca doğa tahribatlarının önlenmesi ile birlikte bitki türlerinin zaten daralmıș olan habitatlarının daha da kısıtlanmasının önüne geçilebilir. Ayrıca Marmaris yarımadasında yerli-yabancı birçok turist gezmekte ve bu kişiler bilerek ya da bilmeyerek bitki türlerine zararlar verebilmektedirler. Bu durumla ilgili koruma çalışmaları ve yöre halkının bilinçlendirilmesiyle bitki türlerinin korunabileceği kanaatindeyiz.

\section{Kaynakça}

[1] Eken, G., Bozdoğan, M., İsfendiyaroğlu, S., Kılıç, D. T., Lise, Y. 2006. Türkiye'nin Önemli Doğa Alanları. Doğa Derneği, Mas Matbaacılık, İstanbul, $473 \mathrm{~s}$.
[2] Carlström, A. 1987. A survey of the flora of Rodhos, Simi, Tilos and the Marmaris peninsula (SE Greece, SW Turkey). Thesis, 302s.

[3] Donner, J. 1990. Distribution Maps to P.H. Davis Flora of Turkey 1-10. Linzer biol. Breitr., 1-135, Linz.

[4] Anonim, 1998. Muğla İli Arazi Varlığı. T.C. Başbakanlık köy hizmetleri genel müdürlüğü yayınları, 132 s., Ankara.

[5] Şenel, M., Bilgin, Z. R. 1997. 1/100.000 ölçekli Türkiye Jeoloji Haritaları, MTA Jeoloji Etütleri Dairesi, Ankara.

[6] Akman, Y., Daget, P. H. 1971. Quelques Aspects Synoptiques des Climats dela Turquie. Bull. Soc. Long. Georg., 5(3), 270-300.

[7] Davis, P. H., Mill, R. R., Tan, K. (eds) 1965-1988. Flora of Turkey and East aegean Islands. Vol.110, Supplement, Edinburg.

[8] Güner, A., Özhatay, N., Ekim, T., Başer, K. H. C. 2000. Flora of Turkey and The East Aegean Islands. Vol. 11, Edinburg Univ. Press, Edinburg.

[9] Güner, A., Aslan, S., Ekim, T., Vura,l M., Babaç, M. T. 2012. Türkiye Bitkileri Listesi (Damarlı Bitkiler). İstanbul Nezahat Gökyiğit Botanik Bahçesi Flora Araştırmaları Derneği Yayını, $1290 \mathrm{~s}$.

[10] IUCN, 2017. Guidelines for Using the IUCN Red List Categories and Criteria, Version 13.0. Gland, Switzerland and Cambridge, UK.

[11] Ekim, T., Koyuncu, M., Vural, M., Duman, H., Aytaç, Z., Adıgüzel, N. 2000. Türkiye Bitkileri Kırmızı Kitabı. Türkiye Tabiatını Koruma Derneği ve Van Yüzüncü Yıl Üniv., Ankara,45s. 